\title{
Leitura e formação inicial de professores: sentidos, memória e história a partir da perspectiva discursiva
}

Filomena ElaineP. Assolini*

Resumo: N esteartigo, apresentamos resultados de uma pesquisa quevem investigando, dentre outras questões, a relação queestudantes do curso de Pedagogia estabeleceram com a leitura ao longo de suas vidas. Buscamos saber seecomo tal relação repercuteno processo deaprendizagem desses licenciandos deforma particular e, em sua formação acadêmica, de maneira ampla. Os postulados teórico-metodológicos da A náli ise de $D$ iscurso de linha francesa propostos por Pêcheux eseusseguidores, bem como as contribuições do referencial histórico-cultural trazidas por C hartier, fundamentam nossas investigações.

Palavras-chave: leitura; aprendizagem; qualificação acadêmica.

Reading and initial teacher education: senses, memory and history based on a discourse perspective

Abstract: In this article, we present the results of a research that has been investigating, among other issues, the relationship that thePedagogy Program students havedeveloped with reading throughout their lives. I t is our intention to find out if and how such relationship influences these graduates' learning process, in a particular way and their academic qualification, in an extensive way. Thetheoretical-methodological postulates from the French Speech Analysis proposed by Pêcheux and followers, as well as the contributions of the historical-cultural referential, brought by $\mathrm{C}$ hartier, substantiate our investigations.

Key words: reading; learning; academic qualification.

\section{I - Fundamentação teórica: conceitos e princípios basilares}

N este artigo, apresentamos resultados de uma pesquisa que investigou, dentre outras questões, a relação que estudantes do curso de Pedagogia estabeleceram com a leitura, ao longo de suas vidas. Buscamos saber se e como tal relação repercute no processo de aprendizagem desses licenciandos, de forma particular e, em sua formação acadêmica, de maneira ampla.

* Professora do Departamento de Psicologia e Educação e Coordenadora do Grupo de Estudos e Pesquisas sobre Alfabetização, Leitura e Letramento (Gepalle) da Faculdade de Filosofia, C iências e Letras de Ribeirão Preto da Universidade de São Paulo (U SP), SP, Brasil. elainefdoc@ ffclrp.usp.br 
O s postulados teórico-metodológicos da Análise de D iscurso de matriz francesa e as contribuições do referencial histórico-cultural trazidos por Chartier e colaboradores, fundamentam nossas análises e discussões.

A Análise de Discurso de matriz francesa (doravante A.D) é um campo de pesquisa fundado por $M$ ichel Pêcheux, no final da década de sessenta. 0 quadro epistemológico da A.D configura-se na articulação de três regiões do conhecimento científico, a saber: a) o materialismo histórico, como teoria das formações sociais, compreendida aí a teoria das ideologias; b) a linguística, como teoria dos mecanismos sintáticos e dos processos de enunciação; c) a teoria do discurso, como teoria da determinação histórica dos processos semânticos.

Essas três regiões do conhecimento são atravessadas e articuladas por uma teoria da subjetividade de natureza psicanalítica.

Pensar os ecos das vivências com a leitura de sujeitos que ocupam a posição de estudantes universitários nos conduz a mobilizar o conceito de memória discursiva, que não deve ser entendida "[... no sentido psicologista de 'memória individual', mas nos sentidos entrecruzados da memória mítica, da memória social inscrita em práticas, e da memória construída do historiador" (Pêcheux, 1999, p. 50).

Cumpre dizer que, de acordo com o enfoque discursivo, o dizer não é propriedade particular; não somos os donos absolutos nem das palavras, nem dos sentidos, o que é dito em outro lugar também significa nas nossas palavras, em nossos dizeres. Sendo assim, destacamos que, segundo G regolin (2007, p. 180), "[...] a memória discursiva é constituída de vestígios que se inscrevem no interdiscurso". 0 interdiscurso, por sua vez, corresponde ao sentido "já-lá", ao "isso fala", e representa o domínio do saber, a memória das formações discursivas, segundo O rlandi (1996, 1999, 2001).

O s processos discursivos não têm, portanto, sua origem no sujeito, mas, sim, na formação discursiva com a qual o sujeito se identifica. Daí podermos dizer que o que existe é a forma-sujeito das formações discursivas com a quais diferentes posições de sujeitos se relacionam. A maneira como determinada posição-sujeito se relaciona com a forma-sujeito evidencia a dispersão do sujeito e a não homogeneidade da formação discursiva, que determina o que pode e deve ser dito (Pêcheux, 1990, p. 160).

$\mathrm{N}$ a A.D , o sujeito é duplamente interpelado: pela ideologia e pelo inconsciente; ele é sempre e, ao mesmo tempo, sujeito da ideologia e do inconsciente, sendo que isso "[...] tem a ver com o fato de os nossos corpos serem atravessados pela linguagem antes de qualquer cogitação" (Henry, 1992, p. 188). Partimos, pois, de um aparato teórico sustentado sob a noção de um sujeito cindido, 
atravessado pelo inconsciente, cujo discurso mantém sempre relação com outros dizeres.

O utro princípio basilar da A.D, que também nos interessa particularmente, é o de condições de produção. O u seja, há uma relação constitutiva entre linguagem e exterioridade. U ma relação orgânica e não meramente adjetiva, supérflua.

Prosseguindo com a nossa fundamentação teórica, ressaltamos que, em oposição à compreensão de leitura como simples e ingênuo gesto de decodificação - leitura essa que permanece centrada no texto, tratado como portador de significação única a ser desvendado e apreendido por um crédulo leitor - , 0 enfoque discursivo concebe leitura como construção e produção de sentidos, porém, nem texto, nem autor, nem leitor, sozinhos, são responsáveis pelos sentidos de um texto.

Chartier (1996), por sua vez, traz para a discussão a concepção de leitura enquanto prática cultural, que obedece às mesmas leis que outras práticas culturais, com a diferença de que ela é mais diretamente ensinada e propagada pelo sistema escolar.

Temos defendido também que leituras (interpretações) múltiplas são possíveis para um sujeito que pode ocupar a posição de "intérprete-historicizado", ou seja, uma posição que permite ao sujeito do discurso produzir sentidos para além da relação termo a termo entre as coisas e a linguagem. (Assolini, 2003)

A presentando o tecido que sustenta teoricamente esta pesquisa, vamos discorrer sobre os aspectos metodológicos.

II - Dispositivo de análise do processo discursivo: a constituição do corpus, a descrição e a escuta discursiva.

O ptamos por trabalhar com entrevistas, pois entendemos, de acordo com Authier-Revuz (1998, p. 97), que "[...] o texto oral, em que não se podem suprimir as reformulações, deixa, mecanicamente, no fio do discurso, os traços do processo de produção".

O fio do discurso, o intradiscurso, permite-nos buscar discursos outros pela memória discursiva (interdiscurso). Amparados por Pêcheux (1990, 1997, 1999), consideramos que tanto o intradiscurso quanto o interdiscurso fazem parte dos fatos discursivos.

Foram por nós realizadas 112 (cento e doze) entrevistas ao longo dos anos de 2007 e 2008; todas elas foram gravadas em áudio e por nós transcritas literal mente. 0 s entrevistados foram sujeitos de diferentes instituições de ensino superior de quatro diferentes cidades do interior paulista. As entrevistas 
foram realizadas em espaços não institucionais, tendo em média uma hora e meia de duração.

A partir desse amplo "espaço discursivo", selecionamos, para o presente artigo, três recortes que serão analisados.

0 aparato teórico-metodológico da A.D. concebe o recorte como "unidade discursiva; fragmentos correlacionados de linguagem e situação" (O rlandi, 1987, p. 139). Em concordância com a citada pesquisadora, optamos por "fatos" e não "dados" de linguagem, pois os fatos têm memória e historicidade. Considerar os fatos linguísticos e neles buscar pistas e vestígios que nos possibilitem compreender se e como a relação que estudantes universitários construíram com a leitura ressoa em seu processo de aprendizagem escolar no âmbito acadêmico implica analisar a inter-relação entre a ordem da língua, a ordem da história e a ordem do discurso.

É válido notar que tanto a AD quanto o referencial histórico-cultural inscrevem-se no paradigma indiciário proposto por Ginsburg (1989), o que nos permite tomar as marcas linguísticas como pistas e indícios para explicar 0 funcionamento das formações discursivas e das formações ideológicas às quais se remetem.

\section{III - G estos de interpretação: perscrutando os indícios e os vestígios nos dizeres de estudantes universitários}

O bjetivamos compreender os fios discursivos que teceram os discursos dos estudantes universitários. Assim, vamos deter-nos, nesta seção, nas análises dos recortes selecionados, em particular nas sequências discursivas de referências S.D.R. - (Courtine, 1982).

\section{Recorteno. 1}

Bom, na minha casa teveo meu pai quelia pra gente, sabe? Ele levava muitosgi bispra gente, a genteficava meio abobadoscom tantosgibisecom tantashistóriasqueelenos contava. Eu comecei a gostar deler com gibis, achava tudo engraçado, legal. C araca, masquando cheguei na universi dadeaí então a gentelêmesmo ostextos pranota, lêpraconseguir a mel hor nota, a notaideal, porque éisso que vale na verdade, né? "N ão leio nada além dos textos da faculdade, porquenão dá tempo, agora eu sou um bom aluno, tenho notasmuito boaseestudo epenso queestou aprendendo a ser capaz demefazer críticasao queleio eao quemeusprofes soresfalam. (Estudante "T")

A análise discursiva do recorte acima nos permite dizer, a partir das sequências discursivas destacadas, que o estudante " $T$ " vivenciou em sua infância experi- 
ências prazerosas com a leitura: "era uma delícia quando meu pai chegava em casa com gibis, a gente adorava". Tais experiências Ihe permitiram aprender, desde cedo, que 0 ato de ler pode estar associado a sentimentos e a emoções caracterizadas pelo encantamento e pela magia: "a gente ficava meio abobados com tantos gi bis e com tantas histórias que ele nos contava". Essas vivências contribuíram para a construção de uma memória de sentidos em relação à leitura na qual " $T$ " pôde ocupar a posição de um sujeito intérprete.

Contudo, quando na posição de sujeito-estudante universitário, " $\mathrm{T}$ " vivencia experiências nas quais se vê obrigado a inscrever-se em formações discursivas caracterizadas pelos ditames de um discurso pedagógico escolar, D.P.E., que valoriza, sobretudo, os aspectos avaliativos tradicionais, no caso, estudar e ler "para conseguir a nota ideal".

N essas condições adversas de produção, a leitura associada ao prazer, à emoção da descoberta e ao encantamento diante do novo e do inusitado cede lugar à leitura-obrigação, à leitura acadêmica, à leitura utilitarista.

As formações ideológicas predominantes na educação superior impõem a circulação de sentidos institucionalizados, cristalizados e legitimados. A ideologia apaga o processo sócio-histórico de constituição dos sentidos, fazendo com que eles se nos apresentem como sendo verdadeiros, únicos, evidentes, naturais. Em outras palavras, predomina na educação superior o processo parafrástico de linguagem, isto é, "o retorno constante a um mesmo dizer sedimentado" (O rlandi, 1987, p. 39). Esse processo conduz o educando a inserir-se em formações discursivas que o levam a acreditar em um mundo "semanticamente normal" (Pêcheux, 1995), sendo que as marcas de um modelo jesuítico-napoleônico de ensino, que ainda se fazem presentes na educação brasileira superior, contribuem para a perpetuação da ilusão de que o "meIhor" aluno é o que alcança as notas mais elevadas.

No recorte em análise, há indícios de que " $\mathrm{T}$ " reconhece que o fato de ter tido oportunidade de constituir-se como um sujeito-leitor em sua infância contribuiu para que sua aprendizagem, quando na posição de estudante universitário, ocorresse significativamente, pois, apesar de estar inscrito em formações discursivas que o colocam na posição de "escrevente", isto é, na posição de um sujeito que somente enuncia sentidos prefixados, consegue desprender-se desse lugar, passando a ocupar a posição de um sujeito que se contrapõe e se inquieta com os discursos estabilizados, originários da reiteração de processos discursivos cristalizados pela instituição escolar.

Esse movimento de migração para outras formações discursivas, o que possibilita ao estudante " $\mathrm{T}$ " questionar os espaços do dizer e as zonas de sentido consideradas legítimas pela instituição escolar, é possível devido a uma memória discursiva marcada por uma relação com a leitura caracterizada pela não 
interdição ao seu dizer e pensar. Assim, " $T$ " pôde, em sua infância, atribuir e produzir sentidos sem interdições ou proibições, o que Ihe permitiu constituir-se como um sujeito-leitor que não se submete a realizar uma simples decodificação textual.

\begin{abstract}
Recorten 0.2
N ão gosto defalar sobreesseassunto, porqueeu chegue a apanhar do meu pai por causa degostar deler, vocêacredita nisso? M eu pai dizia quequem gostava deficar lendo era gayenão queria trabaIhar, ia ser vagabundo. Eu ficava com medo dele, com raiva, me sentia a última das criaturas, uma vez ele chegou a jogar meus livrinhosfora, mechamando demaricas. Tivemuito ódio epassei a ligar uma coisa com a outra, quer dizer, gostar deler com maricagem ebrigascom meu pai. Foi só aqui, na faculdade, com o professor J.V.C.A., quecomecei a ler com gosto, comecei a participar do grupo dele e me apaixonar pela literatura que ele trabal ha e hoje até escrevo melhor. (Estudante" $\mathrm{F}$ ").
\end{abstract}

Iniciamos a análise do recorte acima, destacando que nos chamam a atenção, de imediato, os significantes raiva, ódio e medo. Para o sujeito " $F$ ", a ação de ler remete-o a situações e a vivências nas quais imperavam sentimentos e emoções aversivas em relação a essa prática social. Tais sentimentos e emoções foram intensificados durante os anos correspondentes a sua adolescência, anos esses que o fizeram sentir-se em uma camisa de força, sobretudo no que concerne à leitura escolar.

N essas condições de produção, "F" não consegue constituir-se como um sujeito-leitor, que se vê na condição de saborear uma prática leitora caracterizada pelo prazer e pela sedução advindos de um texto, muito menos aprender que um texto pode constituir-se, por exemplo, em fonte de informação e enriquecimento cultural.

N o âmbito dessa discussão, trazemos a questão do "outro" como constitutivo do discurso. A esse respeito, afirma 0 rlandi (1999, p. 38): "a relação com 0 'outro' regula tudo e preenche tudo, explica tudo, tanto o sujeito como o sentido". Portanto, a heterogeneidade é constitutiva do discurso; e o sujeito que se constitui pela dispersão e pela multiplicidade de discursos, ao enunciar, o faz ocupando várias posições, que marcam a sua heterogeneidade.

Considerando que todo dizer se liga a uma memória de sentidos, a um saber discursivo e tendo por base a concepção de que o sujeito se constitui na relação com o outro, na interlocução com a exterioridade (meio sócio-histórico cultural), assinalamos que, no caso do sujeito " $F$ ", a família, em especial aqueles que ocupam a posição "pai" e "irmão mais velho", contribuiu para que "F" permanecesse inserido em formações discursivas nas quais a prática social da 
leitura é tida como algo destituído de valor e importância cultural. Essas formações discursivas remetem a formações ideológicas que valorizam, sobretudo, o capital e os bens materiais que dele podem advir: "deixe de ler tanta besteira, menino, vai ser jogador de futebol, ficar rico, ganhar muito dinheiro e ter muitos iates" (posição de sujeito "pai").

Como dizem Coracini; Bertholdo (2003), "todo contato com o outro deixa marcas indeléveis, suturas que não podem ser apagadas, como também é impossível apagar as marcas da própria história, inscrições que passam pelo corpo, se fazem carne e sangue" (idem, p. 9).

Tendo em vista o exposto até o presente momento, entendemos ser possível observar que a constituição da memória discursiva do sujeito " $F$ ", referente à leitura, deu-se dentro de condições desfavoráveis de produção, que não Ihe possibilitaram estabelecer vínculos afetivos saudáveis e amistosos com essa prática cultural.

$D$ ando prosseguimento, salientamos que o sujeito " $F$ ", na posição de estudante universitário, parece movimentar-se no sentido de conseguir romper com formações discursivas, nas quais esteve inscrito na infância e na adolescência, a partir da mediação de um sujeito professor, que o convida e 0 instiga à leitura de textos literários, em especial, poemas.

N essa direção, trazemos Pêcheux (1999), que afirma:

umamemória não poderiaser concebida com uma esfera plena, cujas bordasseriam transcendentais históricosecujo conteúdo seria um sentido homogêneo, acumulado ao modo deum reservatório: énecessariamenteum espaço móvel dedivisões, de disjunções, de deslocamento e de retomadas, de conflitos, de regularização[...] um espaço de desdobramentos, réplicas, polê micas e contradiscurso (Pêcheux, 1999, p. 56).

Parece-nos que 0 sujeito-professor universitário que sensibiliza o estudante " $F$ " para a arte das palavras (a literatura), permitindo-Ihe inscrever-se em outras formações discursivas que são marcadas pela aversão à leitura, promove condições de produção que deslocam o sujeito-estudante dessa esfera plena, homogênea, unívoca, em que deslocamentos e contradições não são desejados ou sequer esperados.

A relação com a leitura, ressignificada a partir do contato com textos literários e dentro de condições de produção de leitura que abalam, mexem, remexem e também deslocam os sentidos constituintes da memória discursiva do sujeito " $\mathrm{F}$ " contribui para que possa aprender que a aquisição de conhecimentos, saberes acadêmico-científicos e fazeres pedagógicos aconteça dentro de vivências agradáveis e enriquecedoras, que refletem inevitavelmente na constituição de sua identidade profissional. 
Considerando a tessitura teórica até aqui desenvolvida, podemos destacar que, sendo o sujeito cindido (por assumir várias posições no discurso) e clivado (por ser fragmentado), uma vez que o inconsciente o constitui, seu discurso é sempre heterogêneo. Embora o sujeito acredite, ilusoriamente, ser a fonte de seu discurso, ele nada mais é do que o suporte e o efeito deste.

Complementando nossa argumentação, assinalamos que o conceito de identidade, pensado à luz da A.D. e da psicanálise, pode ser definido como um processo em movimento, em que o sujeito se constitui pela multiplicidade de discurso, pela heterogeneidade e pelo deslocamento (Authier-Revuz, 1990; Coracini; Bertholdo, 2003; Pêcheux, 1990). Adensando essa discussão, trazemos $\mathrm{H}$ all, que propõe pensar em "identidades", sempre fragmentadas, fraturadas, "[... estando em constante processo de mudança e transformação" (H all, 2000, p. 108).

\begin{abstract}
Recorten 03
Tenho lembrançasbacanas demeu avô, quetinha muitoslivrosem casa elia para todosos netos, quesubiam no colo dele, e ele lia e brincava comigo ecom osmeusprimostambém, principalmenteno $N$ atal. M eu avô era o máximo! Eu achava tudo aquilo o máximo. $N$ a adolescência, eu passei a detestar ler... N ãosei dizer o porquê, mas eu gostava mesmo dever TV; eram chatososlivrosda escola. H oje, na faculdade, léo ostextosquando osprofessoresdeixam a gentedizer 0 quesenteepensa, agora eu tedigo uma coisa, tem docentequeexige quea genteescreva do jeito queeleacha quetem queser, igualzinho o queelefalou, assim não dá, parecequea gentefica preso. Só três professores respeitam o quea gentediz. (Estudante "M ")
\end{abstract}

A relação com a leitura, no caso do sujeito "M ", é construída dentro de condições de produção que lhe permitem tomar o outro - no caso o seu avô como modelo a ser seguido: "eu achava tudo aquilo o máximo". A memória discursiva desse sujeito é, assim, caracterizada na sua infância por sentidos que o remetem a emoções e a sentimentos de acolhimento, aconchego e bem-estar.

$N$ essa perspectiva, entendemos que "M", na condição de sujeito estudante universitário, identifica-se com formações discursivas que valorizam a leitura como um instrumento importante para o seu aprendizado. Essa valorização, contudo, não foi construída pela escola, mas edificada, segundo o nosso entendimento, principalmente a partir de um interdiscurso que, sobretudo em sua infância, foi construído e marcado por experiências que o instigaram a ocupar o lugar de um sujeito-intérprete, que pôde, inclusive "brincar com as palavras".

0 que acima expusemos remetenos a um importante postulado da A.D .: 0 interdiscurso disponibiliza dizeres que afetam o modo como o sujeito (se) significa. Sendo assim, é desejável notar que: “[...] nenhuma palavra é 'neutra', 
mas inevitavelmente carregada, ocupada, habitada, atravessada pelos discursos nos quais viveu sua existência socialmente sustentada" (Authier-Revuz, 1990, p. 27).

Considerando que o interdiscurso determina a formação discursiva, podemos dizer que 0 estudante universitário " $M$ " identifica-se com aquelas que lhe permitem realizar leituras e interpretações, principalmente a partir da consideração de sua subjetividade: "lei o os textos quando o professor deixa a gente dizer 0 que pensa e sente". N essa sequência discursiva, é possível constatarmos a concretização da confluência dos eixos da memória (constituição) e da atualidade (formulação).

É válido notar que esse estudante universitário vivencia algumas experiências, em algumas poucas (três) disciplinas do curso de licenciatura em Pedagogia, que lhe permitem ocupar a posição de um sujeito intérprete, condição fundamental, a nosso ver, para que ele possa constituir-se como autor de seu próprio dizer. Contrapomo-nos ao policiamento dos enunciados e dos sentidos que promove a instauração de uma normalização asséptica da leitura, 0 apagamento seletivo da memória histórica e o silenciamento do dizer do educando.

\section{IV - Considerações finais}

As análises e as reflexões por nós realizadas conduzem-nos a destacar a importância de os cursos de formação inicial, particularmente os de Licenciatura em Pedagogia, considerarem que, no processo de aprendizagem do educando, ecoam sentidos já formulados, pois, conforme foi mostrado, todo discurso se delineia na relação com outros dizeres: os presentes e os que se alojam na memória. N ossos discursos são atravessados por outros, em nossas falas fazem-se presentes outras falas; sob as nossas palavras, outras palavras são ditas.

Sendo assim, considerar o interdiscurso em relação à leitura de estudantes universitários pode contribuir para a construção de um trabalho pedagógico que problematize as maneiras de ler, permitindo-Ihes construir uma relação mais arguta com o conhecimento científico. N esse processo, o sujeito ocuparia não o lugar de "escrevente", que tão somente reproduz sentidos e enunciados alheios, mas, sim, de um literato, ou seja, de um sujeito que produz interpretações, por nós concebidas também como atos políticos.

É desejável que os futuros pedagogos, que têm pela frente a complexa tarefa de lidar com os inúmeros desafios de educar crianças e jovens em uma sociedade marcada por transformações histórico-culturais, ideológicas e tecnológicas, dentre outras, possam ocupar o lugar de um sujeito-intérprete (literato), o que Ihes poderia assegurar o permanente exercício da crítica e da autocrítica, condição fundamental para o magistério. Afinal, a docência não requer apenas o domínio 
de conteúdos específicos nas diversas áreas do saber e do ensino, mas também conhecimentos didático-pedagógicos, além da compreensão dos aspectos políticos que sustentam a práxis pedagógica do profissional da educação.

Para encerrar nossas considerações, destacamos que proporcionar aos estudantes de graduação condições de produção para que tenham direito à palavra é um importante passo rumo ao aprimoramento de projetos, propostas e processos de ensino e de aprendizagem que, inevitavelmente, afetam a construção da identidade desse sujeito, que, em sua futura atuação profissional, poderá ocupar ou não a posição de um agente de mudanças e transformações, mas, inevitavelmente, sempre deixará no outro marcas de seu dizer.

\section{Referências bibliográficas}

ASSO LIN I, F. E. P. Interpretação el etramento: os pilares desustentação da autoria. 2003. Tese (D outorado) - FFCLP-USP, 2003.

AUTH IER-REVUZ, J. H eterogeneidade(s) enunciativa(s). C adernosdeestudoslinguísticos, IEL-U nicamp, n. 19, jul./dez. 1990.

AUT H IER-REVUZ, J. Palavrasincertas: as não coincidências do dizer. Campinas: U nicamp, 1998.

CH ART IER, R. Práticas da leitura. Tradução de CristianeN ascimento. São Paulo: Estação Liberdade, 1996.

CORACIN I, M . . .; BERT O LD O , E. S. (O rg.). 0 desejo da autoria ea contingência da prática: discurso sobre/na sala de aula. Campinas: M ercado de Letras, 2003 .

CO RACIN I, M . J. I dentidadeedi scurso: (des)construindo subjetividades. Campinas: Editora daU nicamp ; C hapecó: Argos, 2003b.

COURTINE, J. J. D éfinition d'orientations théoriques et construction de procédures en analyse du discours. Philosophiques, Q uébec, v. 9, n. 2, p. 239-264, oct. 1982.

GIN ZBU RG, C. Sinais: raízes de um paradigma indiciário. In: GIN ZBU RB, C. M itos, emblemas, sinais: morfologia e história. Trad. Frederico Carotti. São Paulo: C ompanhia de Letras, 1989.

GREGO LIN , M . R.; BAR O N AS, R. Análisedo discurso: as materialidades do sentido. 3. ed. São C arlos: Claraluz, 2007.

H ALL, S. A identidadecultural na pós-modernidade. Rio de aneiro: D P\& A, 2000.

H EN RY, P. A ferramenta imperfeita. C ampinas: Editora da U nicamp, 1992.

O RLAN DI, E. P. A linguagem eseu funcionamento. C ampinas: Pontes, 1987.

O RLAN DI, E. P. Asformasdo silêncio: no movimento dos sentidos. 6. ed. Campinas: Editora daU nicamp, 1996. 
O RLAN D I E. P. Análisedediscurso: princípioseprocedimentos. Campinas: Pontes, 1999.

O RLAN D I, E. P. D iscurso etexto: formação ecirculação de sentidos. C ampinas: Pontes, 2001. PÊCH EUX, M .; FU CH S, C. A propósito da análise automática do discurso: atualização e perspectivas. In: G AD ET, F.; H AK, T. (O rg.). Por uma análiseautomática do discurso. C ampinas: Editora da U nicamp, 1990. p. 163-252.

PÊCH EU X, M. Semântica ediscurso: uma críticaà afirmação do óbvio. Campinas: Editora da U nicamp, 1995.

PÊCH EUX, M . Ler o arquivo hoje. In: O RLAN DI, E. P. (O rg.). Getosdeleitura: dahistóriano discurso. 2. ed. Campinas: Editora da U nicamp, 1997.

PÊCH EUX, M . 0 papel da memória. In: ACH ARD , P. 0 papel da memória. Campinas: Pontes, 1999.

Recebido em 15 deoutubro de2010 eaprovado em 10 dedezembro de2010. 
